\title{
Emerging models of power among South African women business leaders
}

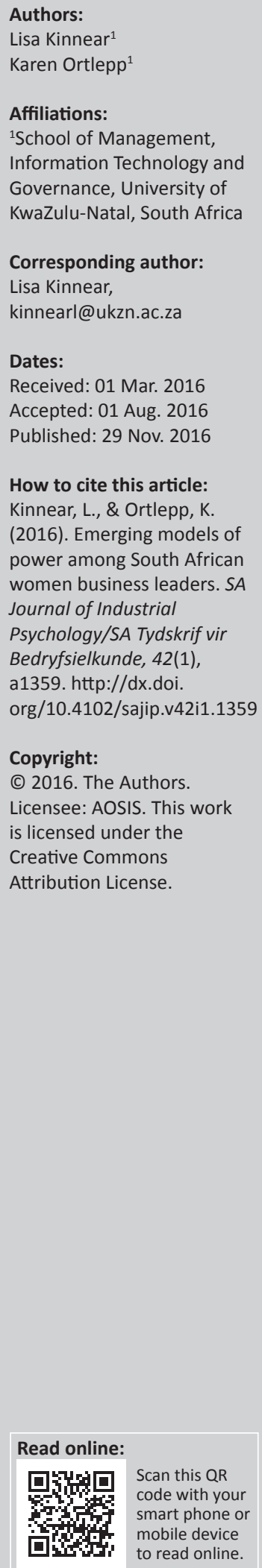

Orientation: This paper represents a broader study which explores how South African women business leaders construct power in their life and leadership narratives. The research was approached with a feminist paradigm in its review of constructions of power and their potential for transformation of patriarchal power dynamics.

Research purpose: The purpose was to critically analyse emerging models of power among South African women business leaders to include their perspectives in the process of theory building.

Motivation for the study: Women in senior leadership positions are not necessarily enabling the transformation of organisations to include greater representation of women at senior levels. A critical understanding of women's models of power may highlight unconscious processes contributing to this as well as emerging models that can facilitate change.

Research design, approach and method: Qualitative research was conducted within a feminist social constructionist framework, using the method of discourse analysis of narrative texts to identify emerging models of power. The 10 women in the study included executives within corporations across a range of industry sectors in South Africa.

Practical/managerial implications: The findings may guide approaches to gender transformation efforts in organisations and raise women leaders' awareness of their conscious and unconscious impact on gender empowerment.

Contribution/value-add: A novel contribution of this study is the emerging transformative model of power and the tensions women experience in asserting this power.

\section{Introduction}

Women remain under-represented in South African corporate leadership along with the rest of the world, despite legislation promoting gender equity (Mall, 2015).The stunted efforts to address this challenge reflect the need to review the ideologies that drive them (Nkomo \& Hoobler, 2014). Studies conducted into gender inequality in business leadership typically focus on representation, but fewer explore women's grapples in exercising power and influencing the agenda of traditional institutions (Stainback, Kleiner \& Skaggs, 2016).

Women leaders' discourse of power needs to be better understood to enable a more conscious approach to gender transformation that takes women's perspectives into account. This article will review women leaders' construction of power within a feminist framework which recognises that leadership and power theories are not neutral because they have been developed within a patriarchal context, resulting in the performativity of gender against restricted set of norms (Butler, 1990; Fletcher, 2004; Lazar, 2005).

\section{Research purpose and objectives}

There is substantial international research focusing on women's experience of power within organisations (Anderson \& Shafer, 2005; Brescoll, 2011; Ely \& Rhode, 2010; Fletcher, 2004; Nicholson \& Caroll, 2013; Powell, 2011; Stead, 2014). However, there are a limited number of South African studies, none of which focus explicitly on power (Franks, Schurink \& Fourie, 2006; Lewis-Enright, Crafford \& Crous, 2009; Martin \& Barnard, 2013). The purpose of the research was to understand South African women business leaders' constructions of power and to develop an emerging model.

The research objectives relating to this purpose were to understand: 
- How women narrate their awareness of power

- How women leaders view and use power in their leadership role

- How women leaders challenge or perpetuate the leadership culture of their organisation

This article reviews the feminist perspectives on power and leadership, which lead to the research objectives and choice of qualitative methodology. It then proceeds to highlight key findings of the research through an emerging model of power.

\section{Literature review}

In this study, power was defined as both relational and personal. Views of power being vested in social relationships such as the control of valued resources as well as agency affecting the attitudes of others (Avelino \& Rotmans, 2009; Fleming \& Spicer, 2014) were considered in the analysis of power models. However, the inner psychological and spiritual attributes of accepting yourself and the evolution of purpose is another important dimension of personal power (Goltz, 2011; Nicholson, 2012). Understanding social, psychological and spiritual power is considered critical to personal and systemic transformation in the field of process psychology (Mindell, 1995). This multi-faceted definition is a postmodern interpretation of power since the Foucauldian notion (1980) of power being constructed in universal 'truths' around the phenomenon is acknowledged.

Feminist theorists illuminate the hegemonic nature of collective thought in relation to power, which has prevented women from defining the concept in their own terms (Ledwith, 2009). The feminist movement, both globally and in South Africa, is characterised by varied perspectives of diverse women. However, a common thread is the need to create consciousness around the female world and to include women's voices in reshaping academic disciplines (Lee, 2010). Feminist redefinitions of power tend to include the transformational power of evolving identity (Dickerson, 2013) and spiritual considerations, which highlight our interconnectedness as human beings with shared responsibility for protecting our environment from acts of oppression (Fletcher, 2004; Ledwith, 2009).

Over a decade ago, Freeman and Borque (2001) argued that power was no longer a male construct and that women were redefining it as personal power, including personal development and self-determination. However Conway (2001) pointed out that the relational emphasis of feminist thought has undermined the power of women to be effective at self-determination because it has denied them of ego. Empirical studies over the years have shown that many women leaders adopt authoritarian models of leadership and are openly criticised for this because a relational approach is expected (Fletcher, 2004). This has resulted in the commonly referenced 'Queen Bee' syndrome; a label given to women who pursue individual success in male-dominated work settings by adjusting to the patriarchal culture and distancing themselves from other women (Derks, Van Laar \& Ellemers, 2016; Johnson \& Marthur-Helm, 2011).The label is regarded sexist by some theorists (Sheppard \& Aquino, 2013) because it problematises women's behaviour that goes against stereotypical expectations of female communality versus male agency.

Women themselves often feel internally conflicted over power and are reluctant to acknowledge their status as either powerful or powerless (Stead, 2014). Many of the current leadership theories argue that in our departure from heroic leadership towards more collaborative leadership, with distributed power, women are expected to perform better than men (Fletcher, 2004; Powell, 2011; Stainback et al., 2016; Valerio, 2009). However, without significant challenge to mental models of how to exercise power, women's supposed focus on collaborative leadership becomes co-opted into mainstream leadership theories and silences its radical challenges to organisational power (Fletcher, 2004).

Gender stereotyping remains at the heart of the challenge women experience in asserting alternative models of power. Much of the literature on leadership compares 'male' and 'female' attributes (Powell, 2011), often using 'male' leadership as the prototype (Booysen \& Nkomo, 2010). What appears assertive, self-confident or entrepreneurial in men is often perceived as abrasive, arrogant and self-promoting in women (Heilman \& Parks-Stamm, 2007). At the same time, when women in authority are seen to be conforming to female stereotypes, they are often liked, but not respected (Eagly \& Carli, 2007). Ely and Rhode (2010) argue that the real challenge facing women leaders is establishing credibility in a culture that is conflicted about their authority. Stereotyping of how authority is performed is equally prevalent when dealing with race and the intersecting effects are difficult to disentangle (Booysen \& Nkomo, 2010; Smith, 2002).

Women's need to prove their worth in the face of gender bias often perpetuates more cautious behaviour associated with management rather than leadership (Ely, Ibarra \& Kolb, 2011). Studies conducted by Ibarra and Obodaru (2009) show that women are perceived to be less visionary than men by their followers, despite contrary evidence. Stereotypical questions around women's confidence leads to their internalisation of inadequacy and lack of self-efficacy (Damaske, 2011; Stead, 2014). Ledwith (2009) argues that it is important for women to determine their leadership styles and exercising of power on their own terms.

Many feminist theorists express women's strength and exercising of power as the recovery of their authentic 'voice' and ability to express it (Brescoll, 2011). Feminist literature points to enlightening and at times painful psychological process of integrating contradictory thoughts and feelings, which challenge the notion of authentic 'self' (Ledwith, 2009; Mahoney, 2001). While the process of journeying towards authentic identity (Dhiman, 2011) is supported by many feminist theorists (Nicholson, 2012), Gardiner (2011) critiques 
the 'authentic leadership' discourse in the literature for failing to recognise the social and historic circumstances that affect a person's ability to become a leader. Leadership studies themselves are not neutral because they take place within a system of power and privilege (Gardiner, 2011). Studies on women in leadership confirm that it cannot necessarily be assumed that occupying a position of leadership gives women equal status and power (Stainback et al., 2016; Valerio, 2009).

Lack of access to high-status colleagues with whom to network is frequently cited as a barrier to women's advancement (Stainback et al., 2016). Research studies reveal that gender stereotypes continue to impact the way women network, causing them to hold back for fear of appearing self-promoting and power hungry (Ely et al., 2011; Heilman \& Parks-Stamm, 2007). Experiences of discrimination and social identity threat can also lead to women in positions of power distancing themselves from women colleagues, for fear of losing the gains that they have made in achieving their status (Derks et al., 2016).

Just as more women gain access to new leadership opportunities, a significant number abandon institutions and forge independent paths to power. They form innovative organisations in which they can employ different leadership styles and possibly pursue a more feminist agenda (Valerio, 2009). Through their entrepreneurial activity, women are asserting their ability to lead on their own terms. In a South African study on retention factors affecting South African women executives, Clark and Kleyn (2007) found that the pull factors for women leaving organisations are to pursue entrepreneurial endeavours in the modern economy, while push factors are to leave paternalistic cultures that do not accommodate their need to make a difference.

The impact of motherhood has often been used as the rationale for excluding women from public leadership roles and women's rejection of these roles has traditionally been associated with family commitments (Bassnett, 2013). However, there is a growing feminist consciousness among women who are not necessarily mothers, yet they are still not enticed by the competitive demands of corporate life (Matchar, 2013). Internalised stereotypes of not being good enough also contribute to women not stepping up to leadership roles (Valerio, 2009). While the absence of significant numbers of women in power remains a challenge, the key question in this research is whether women in positions of power are introducing alternative power models that challenge patriarchal ones.

\section{Research design Research approach}

The qualitative paradigm used was social constructionism within a feminist framework.

Social constructionism appreciates reality as multiple and unfolding (Terre Blanche, Durrheim \& Kelly, 2007). It understands our obedience to dominant cultural norms, yet is critical as it reveals possibilities for being and acting otherwise (Gavey, 2011).

Understanding how gender is performed and power is constructed through women's narratives provided the feminist research framework (Butler, 1990), as did the critical reflection in the process of analysis (Lazar, 2005). The role of critical reflection, according to Foucault (1980), is to deconstruct forces that govern the mind as well as enable the emergence of empowering forces that allow subjects to change their lives (Mortari, 2015).

\section{Research strategy}

As the primary researcher, my experience as an Organisational Development Practitioner guided the strategy in identifying the research method. Working within a social constructionist framework, the researcher's perspective has to be acknowledged, but neither emphasised nor obscured (Cohen \& Mallon, 2001). The research strategy was to gather 10 women's narratives on power in their own terms.

\section{Research method}

\section{Research participants and sampling methods}

Purposive sampling was used to ensure that the interviewees had a significant leadership role and could contribute to the process of theory building (Silverman, 2010). This meant they needed to have control over day-to-day operations, decisionmaking powers and report into the board of directors. All leaders came from large corporations because the study focused on traditional institutions of business. Purposive sampling was used to ensure diversity of industries and race. The predominance of white managers in the sample reflects the racially skewed demographics of corporate leadership in South Africa, according to the South African Business Women's Association Census (Mall, 2015). Table 1 represents the sample demographics:

The initial participant was a woman I knew through an organisational development intervention. She met the criteria

TABLE 1: Demographic representation of sample.

\begin{tabular}{|c|c|c|c|c|}
\hline Race & Industry & Age & Family status & Years with company \\
\hline 3 African people & 3 Financial services & 2 participants $<35$ & 4 were single & $3-5$ years \\
\hline 1 Indian people & 3 Consumer goods & 2 participants $<40$ & 2 were married & $6-10$ years \\
\hline 6 White people & 2 Industrials & 5 participants $<45$ & $\begin{array}{l}4 \text { were married and } \\
\text { had children }\end{array}$ & $\begin{array}{l}1 \text { participant worked with the } \\
\text { company for more than } 10 \text { years }\end{array}$ \\
\hline- & 1 Basic materials & 1 participant > 50 & - & - \\
\hline- & 1 Technology & - & - & - \\
\hline
\end{tabular}


and was interested in participating in the study. Snowball sampling (Silverman, 2010) was used in conjunction with purposive sampling thereafter as each interviewee referred me to another potential participant. Snowball sampling relies on natural social networks and is conducive to feminist studies because power relations between the researcher and participants are reduced (Gavey, 2011).

\section{Research setting}

The interviews took place at the participants' offices. Participants were offered an opportunity to be interviewed off-site but all chose to meet on site. This was more convenient for busy executives giving up $2 \mathrm{~h}$ for the interview. The physical setting did not appear to constrain leaders in sharing their narratives.

\section{Entrée and establishing researcher roles}

The researcher was introduced via e-mail to potential participants referred by previous interviewees. This established trust at the outset because there was a common point of contact.

Candidates were then contacted directly to establish their willingness to participate in the study. The purpose of the research was explained and ethical issues of confidentiality were highlighted. Participants signed an informed consent prior to the interview and were asked for permission to record the interview for transcription purposes.

\section{Data collection method}

The autobiographical narratives of 10 women leaders were collected through a semi-structured interview based on McAdam's Life Story Interview (McAdams, Josselson \& Lieblich, 2006). The interviews asked women to construct their notions of power by telling their life and leadership stories relating to past, present and future strategies. The questions were based on the three research objectives. Limited probing allowed for the flow of their autobiographies as recommended by social constructionist researchers using narrative analysis (Josselson in Wertz et al., 2011).

\section{Recording of data}

Interviews were transcribed verbatim and included notation of non-verbal communication. The researcher also recorded process notes during the interview to highlight what may not have been obvious from listening to the recording.

\section{Data analysis}

The methodology used to analyse the data was discourse analysis. This scrutinises the language of conversations and the way individuals account for their world (Ali \& Khan, 2012; Gavey, 2011). Initial close reading of the interviews was conducted to identify potential power discourses within the text. Features recommended by Terre Blanche et al. (2007) were used to identify and refine these. Two key questions helped to guide the process of analysis. The first was self-reflective questioning by myself, the researcher, to acknowledge how my framework may influence the listening (Gavey, 2011). The second was to identify the effect of the text by asking 'what does the text do?' (Terre Blanche et al., 2007). Because of the vast amount of data, several steps were necessary to extrapolate constructions of power, critically analyse and consolidate them into a model. This paper gives a broad overview of how this process was conducted.

An interview analysis grid was developed for each of the three research objectives. Extracts from the interviews were cut and paste onto the grid for each of the research questions. An example of the grid is provided in Table 2.

Extracts were then clustered across interviews according to common discourses emerging from the text, informed by the literature on power. These clusters were refined through the process of analysis and final discourse clusters gave rise to discourse categories. The discourse clusters were colour coded per category for each interview per research objective as in the examples in Figure 1. Extracts relating to these categories were once again critically reflected on to understand what the text was 'doing' and enable integration into a model:

\section{Strategies employed to ensure data quality and integrity}

To ensure data quality and integrity, Guba's (1981) processes of credibility and dependability were applied to the data. Credibility was achieved by following established methods of discourse analysis, having debriefing sessions with specialists from the University of KwaZulu-Natal and by relating the findings to previous research. Dependability was achieved through detailed reporting of the methods in the

TABLE 2: Interview analysis grid - Research Objective one: To understand how women narrate their awareness of power.

\begin{tabular}{|c|c|c|c|}
\hline Line & $\begin{array}{l}\text { Features: Binary opposites; terms, phrases, } \\
\text { metaphors; human subjects }\end{array}$ & Discourse description & Analysis \\
\hline \multirow[t]{6}{*}{$238-249$} & \multirow{6}{*}{$\begin{array}{l}\text { And I was so upset, and I spent the next sort of hour } \\
\text { running between him and the stupid photocopier } \\
\text { machine photocopying this file and I came home } \\
\text { and I was in tears and I said to my mum ... I can't } \\
\text { believe it I spent } 3 \text { years doing my degree, a year in } \\
\text { post-grad umm I've excelled academically all my life } \\
\text { and here's this } 55 \text { year old man telling me that I } \\
\text { can't flipping photocopy a file properly (laughs) and } \\
\text { I was really upset about it, and at that moment, for } \\
\text { that day, I felt disempowered }\end{array}$} & Competence; Achievement; & Binary opposite = academic achiever; menial job \\
\hline & & Academic Excellence; & $\begin{array}{l}\text { Human subject }=55 \text { year-old-male boss constructed as } \\
\text { undermining her competence }\end{array}$ \\
\hline & & \multirow[t]{2}{*}{ Possible Discourse: Expert Power } & Laughter = absurdity; reflection; observation \\
\hline & & & $\begin{array}{l}\text { Flipping = throw away expletive emphasises absurdity } \\
\text { and outrage }\end{array}$ \\
\hline & & Resilience & $\begin{array}{l}\text { 'For that day' constructing her resilience, not allowing } \\
\text { it to define her }\end{array}$ \\
\hline & & Possible Discourse: Psychological Power & $\begin{array}{l}\text { What she is doing with the text is demonstrating her } \\
\text { psychological resilience as well as expert power versus } \\
\text { senior male rank in organisation }\end{array}$ \\
\hline
\end{tabular}

Note: Interview: Anika. 


\begin{tabular}{|l|l|l|l|}
\hline \multicolumn{3}{|l|}{} \\
\hline Interviewee & Initial descriptor & Discourse clusters & Discourse categories \\
\hline \multirow{4}{*}{ Angela } & Racial and cultural dominance & Racial and cultural dominance & Social rank \\
\cline { 2 - 4 } & Expert power & Expert power and intellectual superiority & Social rank \\
\cline { 2 - 4 } & Manipulation and control & Manipulation and control & Psychological power \\
\cline { 2 - 4 } & Learning and growth & Learning and growth & Psychological power \\
\cline { 2 - 4 } & Questioning legitimate access to power & Legitimacy of power & Feminist discourse \\
\hline \multirow{3}{*}{ Sharon } & Intellectual superiority & Expert power and intellectual superiority & Social rank \\
\cline { 2 - 4 } & Empowerment of others & Learning and growth & Psychological power \\
\cline { 2 - 4 } & Gender equality & The power of challenging patriarchy & Feminist discourse \\
\cline { 2 - 4 } & Female qualities & Authenticity and female identity & Feminist discourse \\
\hline
\end{tabular}

FIGURE 1: Integrating analysis method - Objective one: How women narrate awareness of power.

study so that future researchers could repeat the steps. Reflexivity, a common practice in qualitative research, was also used to legitimise and validate research procedures (Mortari, 2015).

\section{Reporting}

Discourse categories and their corresponding clusters are reported on in the findings. In the broader study, they were discussed per research question and were consolidated in the models of power presented in this article. For the purpose of this brief article, discourse categories are discussed in general using a few extracts as 'mini-narratives' to illuminate findings in the data.

\section{Findings}

The discourses that arose as women spoke of their experiences of power while growing up, in their current leadership role and envisaged future reflected many aspects of power highlighted in the literature. The broad definition of power, incorporating social, psychological and spiritual dimensions was present in their texts. However, unique to their experience as women were narrations of power reflecting their response to the effects of patriarchy and was therefore categorised as 'feminist discourse'. The third research objective that aimed to understand how women challenge or perpetuate the leadership culture solicited specific discourses relating to their engagement with the organisational system. Discourses were categorised as follows:

- Social rank

- Psychological power

- Feminist discourse

- Engagement in the organisational system

\section{Social power}

Social rank relates to externally attributed elements of power bestowed on women by others and perceived to have value in the broader society through access to resources, such as knowledge or status (Fleming \& Spicer, 2014; Mindell, 1995). Common throughout the discourse on social rank is that this form of power needs to be actively sustained. Categories identified in this cluster were:

- Racial and cultural dominance

- Expert power and intellectual superiority
- Informal positions of social prestige and power

- Power relations within the formal hierarchy

The effect of the racial and cultural dominance discourse differed depending on the race of the interviewees, which is not surprising given their vastly different experiences of power, because all the interviewees grew up under apartheid. The challenge of being 'black' in a predominantly 'white' environment resulted in the continuous need to assert claims to power within a social context actively oppressing them. Racial and gender discrimination were inextricably linked in the black interviewees' accounts, reflecting the challenges experienced in isolating race from gender studies (Smith, 2002). Not only is the struggle to assert power evident in their stories, male oppression is also re-asserted by dismissing the hurtful impact of the racist experiences as recounted in the following extract:

'I'd like to think that he [my boss] is a lot more evolved than just being a racist misogynist pig (laughter). So I am going to assume that it is something to do with my personality. That I just happen to be the person that brings out the worst in him. So I don't know if that answers your question? And I know that is probably not the right answer ...' [Zaba, Marketing Executive]

In this extract, she takes on responsibility for her boss's bigoted behaviour, but the irony is evident in the label she gives him and the flippant laughter thereafter. The self-doubt she expresses at the end of the extract and the expectation that I, as the white researcher, am expecting a 'right' answer has the impact of undermining her ability to recognise power abuse for what it is. This is supported by the literature, which highlights that women are conflicted about identifying with a victim status (Stead, 2014).

In contrast, one of the white interviewees' accounts positions racial and cultural awareness as necessary for leaders in South Africa today. However, in telling of her developing awareness of apartheid growing up, her account shifts between the colonial language of domination to more politically correct language. In relation to her current leadership role, the discourse of racial dominance is constructed around strategies to avoid being perceived as a 'racist'.

'I was wondering if this would come up ... when I was there as a senior manager ... and he accused me and another manager of a 
whole lot of things ... one of them being ... racist ... and this MD took the letter and copied it to the whole of the company board and the executive ... and I can tell you right now of everything in my story ... that was probably the most traumatic moment ... uuum ... and I just saw my career go up in flames before me ... uuum ... everyone who made a decision as to whether I would be made a partner had a copy of that letter ... and what it's taught me is that perceptions are incredibly powerful ... it might be wrong but if people perceive you as something ... they can destroy you and ... I learnt a valuable lesson about perceptions.' [Margie, Finance Director]

The political posturing around issues of race and the denial of racism among all interviewees is a significant finding. It suggests that despite their positions of power, women leaders' ability to engage in authentic dialogue around issues of racism and oppression remains limited. It is noted in the literature that there is limited research on how race and gender intersect and impacts the ability to take up authority in organisations (Smith, 2002).

Expert power and intellectual superiority were constructed as women leaders' need to constantly appear competent and sustain credibility. It included excelling academically and mastering oneself in the leadership environment. This reflects the traditional notions of expert power by French and Raven (1959). What was interesting in these women's accounts was the tenuous nature of this power, despite demonstrated, sustainable levels of competence.

Power constructed through informal, yet socially prestigious positions is common in patriarchal 'old boy networks' where powerful people surround themselves with others to protect them. A number of the women related stories from their childhood of constructing power by aligning themselves with powerful, popular informal groups. One interviewee acknowledged her role in consciously colluding with groupbullying behaviours. Imitation of these behaviours was constructed as 'learning about power', which re-asserts oppressive power as a survival strategy.

In relation to their current leadership roles, many of the interviewees spoke about entrenching positional power through the formal organisational hierarchy. This included the traditional rank of seniority in age. However, in one of the interviews, leadership power was constructed as being able to engage with the younger generation of followers rather than 'pull rank'. By personifying herself as the 'cool mum' trying to understand this generation, she narrated her leadership role as an attempt to bridge the generational divide. In this interview, leadership power was constructed as empathy and identification with her followers:

'The dynamics are totally different ... they are like "what's in it for me?" before they do anything ... they take leave on their boyfriend's birthdays ... it's like ... "It's my boyfriend's birthday and I am taking leave, do you mind?"... And I'm like ... but I didn't even take leave on my birthday, or my daughter's ... and that's why I say I keep in touch ... my daughter keeps me ... educated on the young and how they think, the technology, their things, so I am like the cool mum and I come to work and I bring the fun side of things to ... everyone.' [Lerato, Partner]

Hierarchical power was also constructed through the classical recognition of achievements and consequent reputation. In some narratives, the self-sacrificing martyr archetype was associated with this achievement of hierarchical status:

'But females are inclined to be self-reliant and take on the world of responsibilities and chores, without saying "hell no ... I'm not doing that, I'm playing golf on Saturday ... I'd better get someone else to wash the car and do this and that and the next thing". We tend to feel we have to fit it all in ... we just absorb whatever is required to be done and succeed.' [Debbie, Finance Director]

Certain narratives revealed an alternative construction of power in relation to hierarchy. This was the ability to observe the system without becoming fully engaged in it. This was demonstrated in a few of the interviewees' texts not necessarily in what was being said, but in the way it was positioned.

'I think it is very difficult to come in as an outsider, and have credibility ... people wait for you to sink or swim if you come in from the outside you are not accorded the immediate respect ... you have to prove your stripes ... this is still very much an old school environment of "fantastic, you are the new boy on the block, great ... let's see what you can do, and then we'll decide about you, see if you are any good."' [Debbie, Finance Director]

In this extract, the interviewee uses patriarchal, military metaphors to state her point. But she positions herself as an outsider of the system and its script, rather than recounting a personal experience. The challenging observer role she assumes has an empowering effect in that she is able to see the system for what it is and make choices about how she is influenced by it.

\section{Psychological power}

Discourses related to psychological power were evident in all the interviews as the narrators constructed awareness of the internal resources that develop their experience of being powerful. The discourses identified in this cluster were:

- Female identity

- Integration of 'masculine' and 'feminine'

- Manipulation and control

- Learning and growth

The construction of being a woman was the most commonly shared discourse among the interviewees. The accounts of the development of their female identity reflect multiple and contradictory selves. This was apparent in the way they constructed the mother identity. Only two of the interviewees referred to their mothers as role models, whereas fathers were referenced in all the interviews. Yet the interviewees who had children raised motherhood as an integral part of their identity and empowering in contexts outside of work:

'If I didn't have children then maybe I would push it all the way ... but I do ... and I am quite happy with that ... I think that is where also a woman can understand that and is happy with the 
position that she is in ... knowing that she's choosing to balance her life ... whereas I think with men it is always about getting to the top.' [Kim, Finance Manager]

The ability to lead in their own way, where collaboration emerges as an outcome of an instinctive 'female' style, without the erosion of psychological boundaries, was constructed as the antithesis to the disempowered self-reliant martyr, devoid of personal boundaries. Inherent qualities, such as intuition and conscientiousness, were acknowledged as part of this powerful female identity.

However, the integration of male and female qualities through identity construction was also positioned as authentic power:

'I don't know if this happens everywhere, but I've noticed it ... a women when you start talking will smile ... men don't smile ... I think it is interesting ... because there is no need to ... what are we doing it for? Is it to appear more attractive, is it to be a bit subservient ... I don't know what it is. But it's an interesting observation ... that men tend not to smile unless they are joking, of course ... but at a business meeting you don't see that, ...you know men don't smile at each other as they talk ... women do ... which is strange behavior too, I suppose. (laugher) .... We are all here, let's have a good time ... [laugh].' [Vanessa, Regional Manager]

This extract parodies the stereotypical primal instincts of male and female beings. This concurs with the literature where it has been noted that men and women are held to different standards (Fletcher, 2004; Powell, 2011).The effect of the text is to position herself as something of an anthropologist observer of both male and female behaviour. At the same time, when she jokes that 'we are all here, let's have a good time', she mocks the parody and highlights the universal of being human and spontaneously authentic. She positions her leadership identity as neither 'male' nor 'female' but rather as the conscious observer of what happens unconsciously in both.

Several of the women consistently integrated so-called 'masculine' and 'feminine' traits of their leadership style, traditionally constructed as opposites. This integration incorporated balancing professional and/or business and personal and/or relational interests as a leader. Power was constructed as the ability to make tough decisions and motivate teams towards outcomes, while building trust and co-operative relationships. This emerged as a more sustainable model for the construction and re-construction of power than a binary approach.

Manipulation and control as a psychological power construct was narrated through family relations growing up and the archetypal female authority roles in their narratives. These included positioning others and themselves as the conniving political player and emotional blackmailer. Recognition of the potentially abusive nature of these roles differed between interviewees and the extent to which they consciously construct these roles. What emerged in this discourse was the varying degrees to which women take accountability for this behaviour. Some interviewees constructed manipulation as a 'game', whereas others acknowledged its potential for abuse.

'I don't enjoy it necessarily but I know how to push the right buttons and to play the game ... and definitely knowing how to play the game with my father and my grandfather who were not easy people.' [Margie, Finance Director]

'It was a very controlling relationship I felt very manipulated and very stifled and he was a huge negative influence ... in fact when I dated him a second time and we broke up I actually felt better about myself ... Umm I knew that I was stronger and more powerful and I wasn't going to get sucked into his vortex all over again.' [Anika, Partner]

Revelations associated with the learning and growth discourse were not always articulated as a surface structure of the texts. The reflective process of observing and learning from personal and transformative experiences was sometimes accessible in the text and at times more deeply embedded on further analysis:

'We were in a meeting and I could feel the room going quiet when I become quite vocal about an issue and it suddenly dawned on me how much influence or power I had because of my position and I realised I needed to be cautious about how I expressed myself. People don't just hear what I say they associate it with the position. I'm very aware of that ... it was an 'aha' moment.' [Sandy, Divisional Manager]

\section{Feminist discourse}

The impact of patriarchy and women's ways of dealing with it describes the feminist discourse that emerged in their narratives. Categories in this discourse cluster were:

- Legitimacy of power

- The power of challenging patriarchy

- Gender discrimination

It was significant to find that despite their tenure, many women, across the racial spectrum, perpetuated the discourse of doubting their legitimate access to power by second-guessing their appointment as an affirmative action strategy. It was also evident in the undervaluing of their competence and the limitations they experience from domestic constraints. A more enabling discourse was the conscious deconstruction of their internal victimisation by detaching themselves from gender and racial labels.

Women leaders narrated the power of challenging patriarchy in multiple ways. These included operating outside of patriarchal systems by leaving institutions or through the mental process of detachment. Some women spoke of transforming power relations through direct confrontation stemming from their moral convictions. This direct challenge was contrasted with a more subversive approach where bullying behaviour was tolerated and the system was manipulated for personal gain. While this was positioned as a conscious process rather than defensive response, it fails to transform relations in any substantial way: 
'So I got the CA, I got the bursary, I used the bursary for the CA. got the foreign secondment, chalked up that experience, got that on my CV, and said thank you, ciao. And they were like "uhhuhh don't you want to stay on?" and I said "no thanks, I'm not interested in the profession" very politely! I didn't say "because you are a bunch of chauvinists!"' [Lynette, Finance Manager]

Exploiting the system for personal advancement and ultimately rejecting it asserts her individual power in standing up against the system. However, it does not highlight the effects of discrimination. The gender discrimination rhetoric evident in women's narratives presents both disempowerment within and alienation from the patriarchal system as the antithesis of leadership power.

\section{Engagement with the organisational system}

When asked the question about how they intended to influence the leadership culture going forward, women interviewees battled to articulate responses. The discourses that emerged as empowering centred around personal engagement with the organisation:

- Meaningful networks

- Having a valued voice

- Active identification with values and purpose of the organisation

Meaningful networks were positioned as the binary opposite of politically expedient ones. In the former, sincere engagement with others is used to develop power through credibility and integrity, whereas in the latter, alignment and collusion with power structures are used for personal advancement. Linked to this was the questioning of a redefinition of how women relate to and support one another and a call for a sharing of experience among men and women leadership peers.

'I suppose the one thing if I reflect back on my career ... and I guess it comes back to my not being very good at networking ... is I would have liked a bigger network of females in a similar position to me ... that I really could have connected with in a very confidential, open and transparent way.... And I'd like to know how men feel about themselves. That is what I'd like to know. How different are men? Because I've always felt they are quite different, and maybe they aren't really.' [Sandy, Divisional Manager]

Another empowering discourse that emerged was having a valued voice in the organisation. This was positioned through stories relating to the process of constructive exchange and dialogue between various role players in the organisation. Authenticity and congruence between their leadership behaviour and others' expectations emerged as a strategy, supported by the literature (Livingston \& Lusin, 2009), for gaining a voice and sustaining influence at a strategic level.

Support for the organisation's purpose and upholding organisational values with conviction was also constructed as a means of sustaining power. The emphasis was on how actions, rather than rhetoric, speak of their intentions.
Some women constructed power in their future as working outside of the corporate world in a system with a nobler purpose:

'So that's the real question I'm asking myself right now ... will that give me more life satisfaction and feel like I've really made a difference ... umm because sometimes, if I look at a corporate job, as much as I know I have made a difference, I kind of feel like ... I'm out of here someone else will come and carry on ... I know that this is a moment in time and I feel sometimes I could really do something more meaningful.' [Sandy, Divisional Manager]

\section{Discussion}

In the analysis, it became clear that the emerging model of power needed to be located within a broader framework representing the tensions between varying constructions of power. These power tensions (Figure 2) reflect the multiple ways women construct power as they grapple and shift between models in their leadership role. This accommodates contradictions within women's identity and the conscious and unconscious choices they make in response to patriarchal power dynamics (Dickerson, 2013; Gavey, 2011).

\section{Entrenched colluding}

The entrenched colluding model (Figure 2) re-asserts oppressive models of power by colluding with the patriarchal system. Women gain tenure with the system and assimilate these power models into their own constructions. The hostility of the business environment is perpetuated through this power discourse and social rank is confirmed (Freeman \& Borque, 2001; Powell, 2011).

However, the feminist discourse category highlights that this model is further entrenched when women choose to perpetuate their role as victims. This is most significantly illustrated through the inability to recognise or articulate abuse. Women's apparent compliance with psychologically abusive forms of power and the inability to tackle it directly because of its insidious nature has been well documented in feminist research (Gavey, 2011).

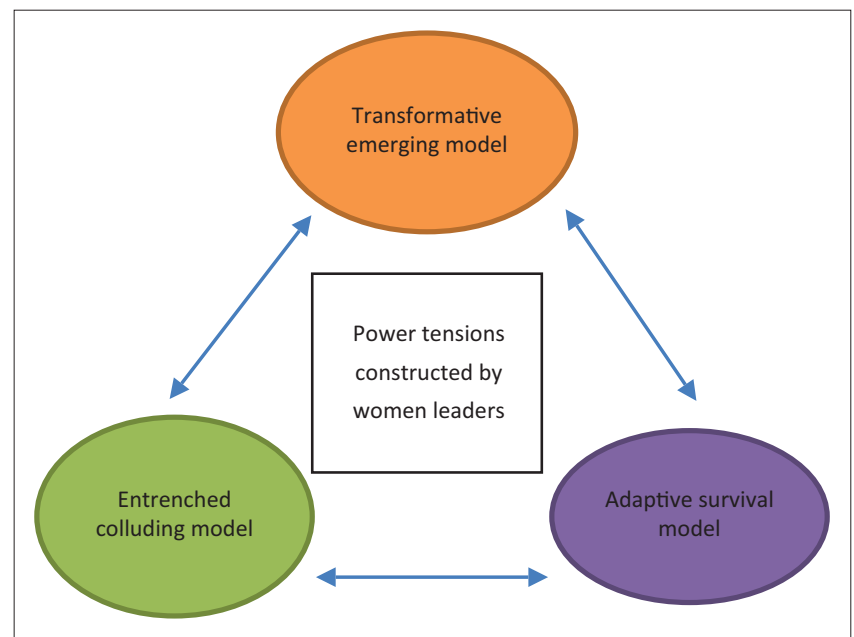

FIGURE 2: Power tensions: Constructions of power of women leaders. 
The clash of domestic roles re-enforces this form of power where women are unable to integrate other identities into their leadership role. Feminist gains made in achieving equality in the workplace will never be sufficient without bringing about change in the way institutions accommodate the role of nurturer (Bassnett, 2013).

\section{Adaptive survival}

The adaptive survival model (Figure 2) reflects women's strategies to adapt to their context in ways that help them survive the system to their advantage, but not necessarily in a way that is sustainable. With its individual survival focus, this model is not conducive to extending power to other women (Derks et al., 2016).

The most explicitly articulated element of this model of power is women's manipulation of the patriarchal system to their advantage, without directly challenging it. This indirect, individualistic approach may be regarded as complicit with traditional power models as it does nothing to constructively dismantle patriarchy. However, this is done more consciously with political astuteness (Valerio, 2009). The focus in this model is how to be effective in a 'man's world' while coopting uniqueness as a woman (Fletcher, 2004; Stead, 2014).

Managing reputation with a view to being respected for expertise and emulated by others is another adaptive behaviour that places women in positions of power. These achievements are empowering in their own right and result in agency and self-actualisation. However, this model requires continuous attention and its focus is on outcomes rather than process. It is an identity constructed out of political expedience to be seen and judged as worthy, but it does not necessarily alter power relations (Nicholson \& Carroll, 2013).

In this adaptive model, the challenge to patriarchy is constructed through women's detachment from or rejection of the system as discussed in the feminist discourse category. Women may choose to disengage from the power dynamics within organisations as a survival strategy and in so doing limit their ability to lead or influence the organisation (Clark \& Kleyn, 2007). Or they may leave corporations because of feelings of alienation, without consciously changing their approach to exercising power (Valerio, 2009).

\section{Emerging transformative}

The emerging transformative model (Figure 3) reflects the discourses that were not as obvious in the surface structure of the narratives, but on deeper analysis shared the potential for transformation of interpretations of power. The discourses relate to the study's initial definition of power, incorporating insights from feminist interpretations, current leadership theories and the process psychology model (Mindell, 1995). These are represented in Figure 3:

- Social - engagement with the community

- Psychological - continuous construction of congruent identity

- Spiritual - transcendence and purpose

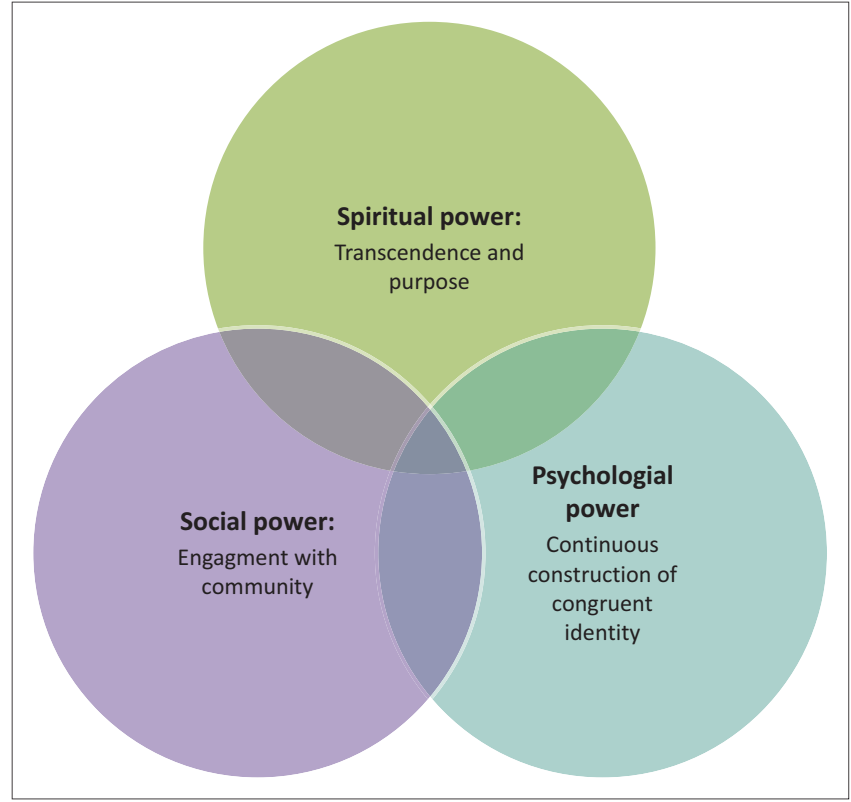

FIGURE 3: Emerging transformative model of power.

While this model of power has potential for transformation, the broader power tensions framework (Figure 3) acknowledges the continued influence of dominant models and complex process of asserting new models.

\section{Social power: Engagement with community}

Social construction of power in this model represents how women interact with those in the broader organisational community, namely followers, peers and superiors. The model emphasises an awareness of power and rank as essential for engaging with stakeholders positively. This awareness allows leaders to deconstruct hierarchies between themselves and others and transform relationships through constructive engagement (Goltz, 2011; Mindell, 1995).

Networks are constructed through sincere engagement in relationships, with integrity, through the process of dialogue as well as the establishment of credibility through actions aligned to their intentions (Livingston \& Lusin, 2009).

Role models are not to be revered, but are powerful through their emotional connections with others and sincere empathy, rather than charismatic reverence (Dhiman, 2011; Livingston \& Lusin, 2009). Personal relationships are powerful in creating 'community' rather than institutional influence at a macro level. The model enables positive transformation of relationships through constructive confrontation of abusive power dynamics.

\section{Psychological power: Continuous construction of congruent identity}

Psychological power represents women's ability to overcome prejudice and build credibility through continuous construction of their identity. It incorporates observations from the literature that identity construction is an ongoing process (McAdams et al., 2006). The process allows for 
integration of several identities, including traditionally regarded 'male' and 'female' qualities (Booysen \& Nkomo, 2010; Fletcher, 2004; Powell, 2011).

The psychological process of power construction allows for personal transformation brought about through selfreflection (Dickerson, 2013). It also re-interprets self-doubt, often negatively associated with ambivalent expressions of women, as a sign of strength in sustaining humility and advocating self-reflection (Ledwith, 2009; Nicholson, 2012). Through reflection, power is constructed as being able to make sense and learn from what are typically intuitive processes and share these with others.

\section{Spiritual power: Transcendence and purpose}

The analysis of the data did not illuminate the discourse of spiritual power as starkly as presented in this model, which is why it was not highlighted as a discrete discourse in the findings. However, tentative constructions of power touched on elements that were reminiscent of spiritual power inherent in Mindell's model (1995) and Goltz's theories (2011). These constructions are regarded as emerging because they are tentatively articulated and may not be as accessible as other discourses, yet they provide an alternative to the hegemonic narratives of patriarchal power.

The construction of spiritual power is evident in narratives where women found a way of transcending the organisational system (Dhiman, 2011; Seligman, 2006). 'Transcendence' in this context is not the same as the detachment described in the adaptive survivor power model. Power is constructed as both transcendent and engaged through the conviction of values and the humility with which they are pursued. Power is derived from meaningful engagement with the system as a participant observer (Goltz, 2011).

By aligning identity with a heightened level of consciousness or 'purpose' as described in the literature (Anderson \& Shafer, 2005; Nicholson, 2012), the spiritual dimension of power is constructed. This discourse emerged as something more profound than simple congruence with the organisation's values and purpose. Personal power that mitigates forms of controlling power emerged as being connected to something greater than oneself or the institution.

\section{Practical implications}

The implication for women in leadership is to recognise how they work with these tensions to enable meaningful personal transformation and be able to lead gender initiatives. Awareness of the impact of power constructions should help women leaders and researchers understand how social context informs their mental models. This knowledge could guide leadership development processes designed for women leaders.

\section{Limitations of the study}

The model represents findings from this study and sample group and cannot be generalised to all women leaders in South Africa. Feminist and social constructionist research makes no excuse for the perspective of the researcher, but incorporates it as part of the critical interpretation of the research. Researchers with backgrounds different from my own would provide a significant contribution to the analysis of women leaders' narratives on power.

\section{Recommendations}

The intersecting effects of race and gender, specifically in the South African context, is an area that warrants further research.

Further research to enrich the robustness of the model and engage with a larger, diverse group of women would continue to add to the theory building of models of power.

Research into the effects of power and gender performativity in leadership roles on the advancement of other women is an area where further research would be valuable.

\section{Conclusion}

Women continue to construct leadership power in terms of traditional, patriarchal models but are tentatively asserting emerging models. However, they grapple with the tensions of colluding with patriarchy and becoming 'one of the boys'; of surviving the system through manipulative tactics; and asserting models of power which transform themselves and their relationships.

It is vital that gender transformation efforts create the space for critical reflection on these tensions and the destructive effects of collusion and adaptation. At the same time, they should support women in co-creating alternatives with the promise of bringing about a different form of leadership that is more sustainable for the demands of our modern world.

\section{Acknowledgements Competing interests}

The authors declare that they have no financial or personal relationships which may have inappropriately influenced them in writing this article.

\section{Authors' contributions}

L.K. designed the research approach and interpreted the findings for her $\mathrm{PhD}$ research. K.O. supervised the PhD study. L.K. wrote the article and K.O. peer reviewed it, as did Dr Shaun Ruggunan of UKZN.

\section{References}

Ali, G., \& Khan, L. (2012). A language and construction of gender: A feminist critique of sms discourse. British Journal of Arts and Social Sciences, 4(2), 342-360.

Anderson, C., \& Shafer, P. (2005). Deeper power. In L. Coughlin, E. Wingard \& K. Hollihan, (Eds.), Enlightened power: How women are transforming the practice of leadership (pp. 55-68). San Francisco, CA: Josey-Bass. 
Avelino, F., \& Rotmans, J. (2009). Power in transition: An interdisciplinary framework to study power in relation to structural change. European Journal of Social Theory, 12(4), 543-569. http://dx.doi.org/10.1177/1368431009349830

Bassnett, S. (2013). Feminist experience: The women's movement in four cultures, Vol. 11. London: Routledge.

Booysen, L., \& Nkomo, S. (2010). Gender role stereotypes and requisite managemen characteristics: The case of South Africa. Gender in Management: An Internationa Journal, 25(4), 285-300. http://dx.doi.org/10.1108/17542411011048164

Brescoll, V. (2011). Who takes the floor and why: Gender, power, and volubility in organizations. Administrative Science Quarterly, 56(4), 622-641. http://dx.doi. org/10.1177/0001839212439994

Butler, J. (1990). Gender trouble: Feminism and the subversion of identity. New York: Routledge.

Clark, D., \& Kleyn, N. (2007). Why do they leave? Voluntary turnover of South African women executives. Unpublished master's thesis, Gordon Institute of Business Science, Pretoria, South Africa.

Cohen, L., \& Mallon, M. (2001). 'My brilliant career?' Using stories as a methodological tool in careers research. International Studies of Management and Organisation 31(3 Fall), 48-68. http://dx.doi.org/10.1080/00208825.2001.11656820

Conway, J. (2001). Amazons and warriors: The image of powerful woman. In S.J.M Freeman, S.C. Bourque \& C. Shelton (Eds.), Women on power: Leadership redefined (pp xi-xxiii). Boston, MA: North-Eastern University Press.

Damaske, S. (2011). A 'major career woman?' How women develop early expectations about work. Gender and Society, 25(4), 409-430. http://dx.doi.org/10.1177/ 0891243211412050

Derks, B., Van Laar, C., \& Ellemers, N. (2016). The queen bee phenomenon: Why women leaders distance themselves from junior women. The Leadership Quarterly, 27(3), 456-469. http://dx.doi.org/10.1016/j.leaqua.2015.12.007

Dhiman, S. (2011). Personal mastery and authentic leadership. Organisational Development Journal, 29(2 Summer), 69-83.

Dickerson, V. (2013). Patriarchy, power, and privilege: A narrative/poststructural view of work with couples. Family Process, 52(1), 102-114. http://dx.doi.org/10.1111/ famp.12018

Eagly, A.H., \& Carli, L.C. (2007). Through the labyrinth: The truth about how women become leaders. Boston, MA: Harvard Business School.

Ely, R., Ibarra, H., \& Kolb, D. (2011). Taking gender into account: Theory and design for women's leadership development programmes. Academy of Management and Learning Journal, 10(3), 474-493.

Ely, R.J., \& Rhode, D.L. (2010). Women and leadership: Defining the challenge. In N. Nohira \& R. Khurana (Eds.), Handbook of leadership theory and practice (pp. 377-410). Boston, MA: Harvard Business Publishing.

Fleming, P., \& Spicer, A. (2014). Power in management and organization. The Academy of Management Annals, 8(1), 237-298. http://dx.doi.org/10.1080/19416520.201 of Managem
4.875671

Fletcher, J. (2004). The paradox of postheroic leadership: An essay on gender, power and transformational change. The Leadership Quarterly, 15, 647-661. http:// dx.doi.org/10.1016/j.leaqua.2004.07.004

Foucault, M. (1980). Power/knowledge: Selected interviews and other writings 1972 1977. New York: Random House Digital Inc.

Franks, K., Schurink, W., \& Fourie, L. (2006). Exploring the social construction of life roles of career-oriented women. South African Journal of Industrial Psychology, 32(1), 17-24. http://dx.doi.org/10.4102/sajip.v32i1.222

Freeman, S., \& Bourque, S. (2001). Leadership and power: New conceptions. In S. Freeman, S. Bourque \& C. Shelton (Eds.), Women on power: Leadership redefined (pp. 3-24). Boston, MA: North-Eastern University Press.

French, J., \& Raven, B. (1959). The basis of social power. In D. Cartwright \& A. Zander (Eds.), Group dynamics (pp. 150-167). New York: Harper \& Row.

Gardiner, R. (2011). A Critique of the discourse of authentic leadership. Internationa Journal of Business and Social Science, 2(15), 99-104.

Gavey, N. (2011). Feminist poststructuralism and discourse analysis revisited. Psychology of Women Quarterly, 35, 183-188. http://dx.doi.org/10.1177/0361684310395916

Goltz, S. (2011). Spiritual power: The internal, renewable power source. Journal of Management, Spirituality and Religion, 8(4), 341-363. http://dx.doi.org/10.1080 /14766086.2011.630171

Guba, E.G. (1981). Criteria for assessing the trustworthiness of naturalistic inquiries Educational Communication and Technology, 29, 75-91.

Heilman, M.E., \& Parks-Stamm, E.J. (2007). Gender stereotypes in the workplace: Obstacles to women's career progress. In S.J. Correll (Ed.), Social psychology of gender: Advances in group processes (pp. 47-77). Greenwich: JAI Press.

Ibarra, H., \& Obodaru, O. (2009). Women and the vision thing. Harvard Business Review, 87(1), 62-70.

Johnson, Z., \& Marthur-Helm, B. (2011). Experiences with Queen Bees: A South African study exploring the reluctance of women executives to promote other women in the workplace. South African Journal of Business Management, 42(4), 47-55.
Lazar, M. (2005). Politicizing gender in discourse: Feminist critical discourse analysis as political perspective and praxis. In Lazar M. (Ed.), Feminist critical discourse analysis: Gender, power and ideology in discourse (pp. 1-28). Basingstoke: analysis: Gender, pow

Ledwith, M. (2009). Antonio Gramsci and Feminism: The elusive nature of power. Educational Philosophy and Theory, 41(6), 684-697. http://dx.doi.org/10.1111/j. 1469-5812.2008.00499.x

Lee, L. (2010). Sex-gender oppression, sociolinguistics, feminism, triad of power. Journal of Critical Studies in Business \& Society, 1(1-2), 55-93.

Lewis-Enright, K., Crafford, A., \&Crous, F. (2009). Towards a workplace conducive to the career advancement of women. South African Journal of Industrial Psychology, 35(1), 1-9.

Livingston, D. \& Lusin, J. (2009). A prescriptive hybrid model of leadership: Complexity leadership theory and authentic leadership theory. In Proceedings of the European Conference on Management, Leadership \& Governance, The George Washington University, USA, pp. 102-109.

Mahoney, M. (2001). The problem of silence in feminist psychology. In S. Freeman, S. Bourque \& C. Shelton (Eds.), Women on power: Leadership redefined (pp. 61-83) Boston, MA: North-Eastern University Press.

Mall, F. (2015). Preface: The importance of gender inclusivity. Business in Women Leadership Census 2015, Business Women Association of South Africa 6-9.

Martin, P., \& Barnard, A. (2013). The experience of women in male-dominated occupations: A constructivist grounded theory inquiry. South African Journal of Industrial Psychology, 39(2), 1-12. http://dx.doi.org/10.4102/sajip.v39i2.1099

Matchar, E. (2013). Homeward bound: Why women are embracing the new domesticity. New York: Simon and Schuster.

Mauthner, N.S., \& Edwards, R. (2010). Feminist research management in higher education in Britain: Possibilities and practices. Gender, Work and Organization 17(5), 481-502. http://dx.doi.org/10.1111/j.1468-0432.2010.00522.x

McAdams, D., Josselson, R., \& Lieblich, A. (2006). Identity and story: Creating self in narrative. Washington, DC: American Psychological Association.

Miller, J.B. (1982). Women and Power, colloquium, Work in Progress Series 82-01. Stone Centre for Developmental Services and Studies. Wellesley, MA: Wellesley College.

Mindell, A. (1995). Sitting in the fire. London: Arkana.

Mortari, L. (2015). Reflectivity in research practice: An overview of different perspectives. International Journal of Qualitative Methods, 14(5), 1-9. http:// perspectives. International Journal of Q
dx.doi.org/10.1177/1609406915618045

Nicholson, S. (2012). Neither God nor Goddess: Why women need an archetype of the self. Journal of Integral Theory and Practice, 7(2), 19-29.

Nicholson, H., \&Carroll, B. (2013). Identity undoing and power relations in leadership development. Human Relations, 66(9), 1225-1248. http://dx.doi.org/10.1177/ 0018726712469548

Nkomo, S., \& Hoobler, J. (2014). A historical perspective on diversity ideologies in the United States: Reflections on human resource management research and practice. Human Resource Management Review, 24(3), 245-257. http://dx.doi.org/10. 1016/j.hrmr.2014.03.006

Powell, G. (2011). The gender leadership wars. Organisational Dynamics, 40, 1-9. http://dx.doi.org/10.1016/j.orgdyn.2010.10.009

Seligman, M.E.P. (2006). Learned optimism: How to change your mind and your life. New York: Vintage.

Sheppard, L., \& Aquino, K. (2013). Much ado about nothing? Observers' problematisation of women's same-sex conflict at work. Academy of Management Perspectives, 27, 52-62. http://dx.doi.org./10.5465/amp.2012.0005

Silverman, D. (2010). Doing qualitative research. (3rd edn.). London: Sage.

Smith, R. (2002). Race, gender and authority in the workplace: Theory and research. Annual Review of Sociology, 28, 509-542. http://dx.doi.org/10.1146/annurev. soc.28.110601.141048

Stainback, K., Kleiner, S., \& Skaggs, S. (2016). Women in power: Undoing or redoing the gendered organization? Gender and Society, 30(1), 109-135. http://dx.doi. org/10.1177/0891243215602906

Stead, V. (2014).The gendered power relations of action learning: A critical analysis of women's reflections on a leadership development programme. Human Resource Development International, 17(4), 416-437. http://dx.doi.org/10.1080/13678868. 2014.928137

Terre Blanche, M., Durrheim, K., \& Kelly, K. (2007). First steps in qualitative data analysis. In M. Terre Blanche, K. Durrheim, \& D. Painter (Eds.), Research in practice: Applied methods for the Social Sciences (pp. 320-344). Cape Town: University of Cape Town Press.

Valerio, A. (2009). Developing women leaders. New Jersey: Wiley-Blackwell.

Wertz, F., Charmaz, K., McMullen L., Josselson R., Anderson, R., \& McSpadden, E. (2011). Five ways of doing qualitative analysis. New York: The Guildford Press. 